\title{
ARTICLE
}

\section{The political economy of medical ethics}

\section{RAVI DUGGAL}

Centre for Enquiry into Health and Allied Themes. Survey No. 2804-2805, Aaram Society Road, Vakola, Mumbai 400055, India. email: raviduggal@ vsnl.com

Munnabhai, the don who takes on the mantle of ethics in medical practice in the film Munnabhai $M B B S$, is the quintessential response to the death of ethics in the medical profession. Munnabhai fails to become a doctor and rightly so, but he sends a message to the medical profession which is convinced of its own greatness and preoccupied with amassing fortunes from people's misery: Medicine is a service that cannot be governed by 'cold' science alone. It must have a human touch.

Medical practice deals directly with humans, and interventions by medical professionals are often a matter of life and death. Medical knowledge and technology put practitioners in a position from where they can wield exceptional influence. Practitioners must balance this power with ethical conduct. They are obliged to follow and respect the code of ethics which they vow to uphold when they graduate.

In a political economy that is increasingly being controlled by the market-an unregulated market in the case of health care-ethics assumes great significance. Today, in India, ethics and economics are seen as adversaries. The common belief is that if you are ethical you cannot make money-or if you want to make money then you have to forsake ethics. As is always the case, the truth lies somewhere in the middle.

In India, public health services do not meet the needs of the people. What is worse, investment and expenditures on public health are rapidly declining even as there is an increasing trend to introduce user fees for public services. If we view health care as a right, as it is in many countries of the world, then the state is violating human rights and consequently being unethical. In fact, since the Indian government has ratified the International Covenant for Economic, Social and Cultural Rights, it is obliged to assure basic health care as a right to its citizens. This obligation is even more important given the widespread poverty in India.

Though providing social security to the poor is an ethical duty of the state, in India, health care provision is largely in the market domain. Even the poor often have to depend on the market because of inadequate access to public health services. For this reason, the ethical conduct of medical practitioners becomes important.

Why is medical practice largely characterised as unethical? The most obvious answer seems to be economics-it is all about money, honey! However, when we carefully look at the issue, the medical profession and its fraternity emerge as the culprits. The medical profession has a definitive class character. Doctors by and large come from families with reasonable financial resources. Thus, it cannot be all about money. Further, not only quacks but mainstream professionals also indulge in unethical practices.

The market may have created the environment for unethical conduct but it is the professional who has succumbed to it. This has happened because the medical fraternity functions like a guild and not as a professional association. Most associations are concerned with their interests, not the honour of the profession or the protection of their clients who are the very reason for the profession's existence. Doctors have succumbed to the marketing practices of pharmaceutical companies. They accept commissions for referrals; have misused technologies for personal gain; have issued irrational prescriptions for drugs and investigations, etc. Such practices compromise the patient's interests for the doctor's personal benefit.

As a result, the profession is discredited. Patients have lost their faith in the profession. The practitioner is seen as a trader, not as a professional. While technology may have enhanced doctors' medical skills and capabilities, they lose out on clinical skills by becoming dependent on technology. Unfortunately, this dependence is governed by market pressures, not scientific practice. Technology has become the means to make more money faster-more often than not, through its misuse. Sexselection and sex determination are classic examples of the unethical use of medical technology and knowledge. Sometimes unethical medical practices even get involved in crime syndicates as has happened in the case of kidney transplantations. 
To change this scenario, the profession and its associations must reaffirm the need for a code of ethics. Ethical practice can help cut costs by reducing unnecessary procedures. It can also help resolve many dilemmas that doctors face in their practice under pressure of markets.

However, ethics cannot be practised by a few individuals; it has to become both a norm and a standard. The onus of this is on the professional associations who must insist on ethics in medical practice. They have to launch a major drive to educate their fraternity to begin with. They must also lobby to introduce ethics in medical education curricula.
To support ethical practice, standard treatment protocols have to be developed, minimum standards in practice through accreditation have to be established, and a system of regular audit of medical practice has to be instituted. All this has to be done through self-regulation. Professionals must not wait for the government or insurance companies to step in and try to clean up the system. We have seen failures of the government in regulating sex-selection, organ transplant rackets, etc. It is time the profession learnt to uphold its honour. Professionals will have to condemn those who behave unethically and 'blow the whistle' when needed. They should not shy away from doing this. Otherwise, there will only be further disrepute or, worse still, a Munnabhai will step in to teach them a lesson!

\section{Calling for participation in a survey on sexual harassment in the workplace in India by AMCHSS, Thiruvananthapuram}

A survey on sexual harassment in the workplace is being conducted by Achutha Menon Centre for Health Science Studies (AMCHSS), Sree Chitra Tirunal Institute of Medical Science and Technology, as part of a project to study gender issues in medical education. This study is being facilitated by the Indian Journal of Medical Ethics.

The principal investigators for this study, Dr Mala Ramanathan, Associate Professor, AMCHSS; Dr Sukanya, Independent Researcher, and Dr Sankara Sarma, Additional Professor, AMCHSS, have developed a questionnaire on the subject.

The information in the questionnaire will be collected in a way that maintains anonymity of both the respondents and their institutions. Respondents need not give their names or those of their institutions.

We request you to fill an electronic version of the questionnaire containing about 20 questions, available at the website of the Indian Journal of Medical Ethics (www.issuesinmedicalethics.org). This can be filled in and submitted electronically, without having to reveal your name and even your e-mail.

Alternatively, you can use the questionnaire that appeared in the April-June 2004 issue of the Indian Journal of Medical Ethics and mail the completed forms to the office of the Executive Editor. (Photocopies of the questionnaire will also be accepted.)

Anonymity of the responses is assured. 